\title{
Agriculture Land Classification Based on Climate Data Using Big Data Analysis
}

\author{
M. Sirish Kumar ${ }^{1}$, S. Jyothi ${ }^{2}$ and B. Kavitha ${ }^{3}$ \\ ${ }^{1}$ Research Scholar, Department of Computer Science, Rayalaseema University, Andhra Pradesh, India \\ ${ }^{2}$ Professor, Department of Computer Science, Sri Padmavati Mahila Visva Vidyalayam, Tirupati, Andhra Pradesh, India \\ ${ }^{3}$ Lecturer, Government Degree College, Kalahasthi, Andhra Pradesh, India \\ E-Mail: sirishmca@gmail.com, jyothi.spmvv@gmail.com, ballikavitha@yahoo.co.in
}

\begin{abstract}
The Agricultural Land Classification (ALC) provides a frame work for classifying land according to the extent at which it's physical or chemical characteristics impose long-term limitations on agricultural use. The major physical factors that influence agricultural criteria for grading are based on their physical margins of land for agricultural use, such as climate (temperature, rainfall, aspect, exposure and frost risk), site (gradient, micro-relief and flood risk) and soil (texture, structure, depth and stoniness and chemical properties which cannot be corrected) and exchanges these factors as soil wetness, draughtiness and erosion. These factors together interact with the basis for classifying land into one of five grades, the grade or sub-grade of land being determined by the most limiting factors that can be classified into grades from 1 (excellent) to 5 (very poor). These grades are classified by using temperature and average rain fall. In this we classified Agriculture Land Classification (ALC) by using Big Data Analysis based on climatic conditions of England and Wales data.Here we analyzed England and Wales data because it has the accurate climatic grades data. These grades data is huge so we analyses the data in Big DATA analysis.

Keywords: Agriculture Land, Classification, Grades, Sub Grades, Big Data, Climate, Soli
\end{abstract}

\section{INTRODUCTION}

The Agriculture Land Classification (ALC) [7] was derived and introduced in 1960s outlined the national system[12] where the advice given by the Ministry of Agriculture Fisheries and Food (MAFF) and Welsh Office Agriculture Department (WOAD) on land use planning matters. Agriculture Land [2] quality varies from place to place. The ALC [11] provides the assessing the quality of farmland to enable informed choices to made future use within the planning system. It helps to understand the principles of sustainable development. The ALC classifies [4] land into different types of grades which is used to categories land on ALC maps are as follows:

Grade 1 - Agricultural Land with Excellent Quality: Land with less or very slight limits to agricultural with very wide range of agricultural and horticultural crops will grows that includes top fruit, soft fruit, salad crops and winter harvested vegetables. Yields are more and fewer variables on land at lower quality.

Grade 2 - Agricultural Land with Very Good Quality: Land has slight limits that affect the crop yield, cultivations or harvesting. The agricultural and horticultural crops are usually grown in some land and the grades may reduce flexibility, by that difficulty may arise in the production and the demanding crops such as winter harvested vegetables are root crops. The level of yield is normally high but it will low or more variable than Grade 1.

Grade 3 - Quality Agricultural Land with Good to Moderate: Land has modest limits that affect the alternative of crops, timing and sort of cultivation, harvesting or the level of yield. The demanded crops are grown and are generally lower or more variable than on land in Grades 1 and 2 .

Grade $3 a$ - Agricultural Land With Good Quality: Land which is capable to produce moderate high yields for a narrow range of arable crops or moderate yields of a wide range of crops like cereals, grass, oilseed rape, potatoes, sugar beet and that has less demanding horticultural crops.

Grade $3 b$ - Agricultural Land with Moderate Quality: Land which has the moderate yields of producing a narrow range of crops or lower yields of a wider range of crops or extra yields of grass which are grazed or harvested more in the year.

Grade 4 - Agricultural Land with Poor Quality: Land has cruel limits that significantly restrict the range of crops and/or level of yields. It is primarily apt for grass with occasional areable crops (e.g. cereal and feed crops) the yields which are changeable. In moist climates, yields of grass may be moderate to high but there may be difficulties in utilization. The grade also includes more droughty arable land.

Grade 5 - Agricultural Land with Very Poor Quality: Land has very cruel limits which contain the stable pasture or rough grazing, except for rare pioneer forage crops.

\section{LOCATION AND ALTITUDE DATA}

A. National Grid: The data are referenced according to the national grid of the ordnance survey which has a false at zero easting and zero northing to the south-west of the Isles of Scilly. Grid references are used to locate grid points and to calculate the distance between grid points and intermediates points. 
1. Altitude (ALT): The altitude data (ALT) were obtained from $0.5 \mathrm{~km}$ resolution dataset of representative altitudes held by the Meteorological Office, Bracknell. The values are given in meters $(\mathrm{m})$

B. Rainfall: The rainfall data are averages in millimetres $(\mathrm{mm})$ based on records from several thousand rain gauges for the years 1941-70, which is the current international standard period.

1. Average Annual Rainfall (AAR): Average annual rainfall values were plotted onto a 1:250,000 scale topographic base map and isohyets drawn manually. Grid point values were obtained by interpolation using this base map. The published 1:625,000 map of AAR was also derived from the 1:250,000 base map. AAR is used in the assessment of the overall climatic limitation and was used to derive the altitude adjustments for moisture deficit.

2. Lapse Rate for Average Annual Rainfall (LR_AAR): The rate at which rainfall changes with altitude is used to enable grid point values of AAR to be interpolated for intermediate locations between Grid points taking account of altitude changes. The lapse rate dataset was derived from the AAR and ALT data sets to give a lapse rate for each $5 \mathrm{~km}$ Grid point.

3. Average Summer Rainfall(ASR): Average summer rainfall was calculated for the period April to September. Rain gauge values were plotted on to a 1:625, 00 scale topographic map, isohyets drawn and grid point values interpolated following the producer used for AAR.

C. Temperature: Temperature data from the complete agro-met dataset were accumulated above $0^{0} \mathrm{C}$ using the established algorithm. For Median values in day ${ }^{0} \mathrm{C}$ for January to June (AT0) and April to September (ATS) were calculated.

1. Accumulated Temperature, January to June(AT0): Temperature is strongly related to altitude, latitude and longitude. This relationship can be expressed as a regression model in the form of equation 1 which was fitted to the AT0 data from the complete Agro met dataset. The regression method for calculating Gridpoint AT0 data was found to be more accurate than attempting to plot and analyse the data on a map, and interpolate from such a map

$\mathrm{ATO}_{\mathrm{g}}=1708-1.14 \quad \mathrm{ALT}_{\mathrm{g}}-0.023 \quad \mathrm{EAST}_{\mathrm{g}}-0.044$ $\mathrm{NORTH}_{\mathrm{g}}---(1)$

Where

$\mathrm{ATO}_{\mathrm{g}}$ is the Gridpoint value of AT0 for insertion in the dataset (day ${ }^{0} \mathrm{C}$ )

$\mathrm{ALT}_{\mathrm{g}}$ is the altitude of the grid point obtained from the dataset $(\mathrm{m})$

EAST $_{\mathrm{g}}$ is the National Grid easting to $100 \mathrm{~m}$, in full numeric form

$\mathrm{NORTH}_{\mathrm{g}}$ is the National Grid northing to 100, in full numeric form
Equation 1 explains $88 \%$ of the variation in AT0 and shows the lapse rate of AT0 as 1.14 day ${ }^{0} \mathrm{C} / \mathrm{m}$. This equation for AT0 compares closely with that calculated for similar data. AT0 used in combination with AAR to access the overall climate limitation and in the derivation of the altitude adjustments for moisture deficit.

2. Accumulated Temperature, April to September (ATS): Grid point ATS values were obtained directly from AT0 and national grid easting using equation 2 . This equation was derived from an analysis of station data from the complete agromet dataset and explains $95 \%$ of the variations in ATS

$\mathrm{ATS}_{\mathrm{g}}=611+1.11 \mathrm{ATO}_{\mathrm{g}}+0.042 \mathrm{EAST}_{\mathrm{g}}--(2)$

Where

$\mathrm{ATS}_{\mathrm{g}}$ is the Grid point value of ATS for insertion in the dataset $\left(\right.$ day $\left.{ }^{0} \mathrm{C}\right)$

$\mathrm{ATO}_{\mathrm{g}}$ is the Grid point value of AT0 for insertion in the dataset $\left(\right.$ day $\left.{ }^{0} \mathrm{C}\right)$

$\mathrm{EAST}_{\mathrm{g}}$ is the National Grid easting to $100 \mathrm{~m}$ in full numeric ATS is used in combination with ASR to calculate moisture deficits.

Due to the large data we cannot handle this data normally. So, we analyze this data by using Big data Analysis

D. What is Big Data: From the customer point of view, big data [3] is not new. A major reason for creating data warehouses in the 1990s was to store large amount of data. This Big data is stored in terabyte which is also called as Teradata, a leading data warehousing vendor, used to recognize customers when their data warehouses reached a terabyte. The big data is differentiated easily and handled by traditional relational data base management systems (RDBMSs). Some members consider terabytes to be Big Data but it is changes over time as organizations collect, store and analyze more data. Another point of view it is characterize big data as having high volume, high velocity, and high variety. [15]

High Volume - the quantity of data

High Velocity - at which data is created

High Variety -- the types of data

In another way Big Data is defined as that data that has high volume, high velocity and high variety requires new technologies and techniques to capture, store and analyze and it is used to make decision making provide insight and discovery and support and optimize processes. It is important to understand what to thought big data is and in feature we can see more in Big Data [9].Many data sources are currently untapped and there are utilized. For example every customer e-mail, customer- service chat and social media comment may be captured, stored and analyzed for better understand client sentiments. Web browsing data may capture every movement of mouse in order to better understand of clients shopping.

1. Big Data Sources: Big data may have many sources. For example every click on a web site is captured in web log files and analyzed for better understand of buyer's behaviour and they dynamically recommend products. Social media sources like Face book and Twitter generates 
more amounts of comments and tweets. This data can be captured and analyzed for understand, for example new products like machines like smart meters, generate data. These meters continuously stream data about electricity, water and gas consumption. There is a terrific amount of geospatial data that is created by cell phones that can be used to know the locations of friends and receive offers for nearby stores and restaurants. Image, voice and audio data can be analyzed for applications such as facial recognition system in security systems.

2. Big Data Analytics: The stored data which don't make business value which is a true traditional database, data warehouses and the new technologies such as Hadoop for storing data. The stored data can be analyzed, which can create terrific value. A range of analysis technologies, approaches and products have emerged that are especially applicable to big data [8], likely in-memory analytics, indatabase analytics and appliances

3. What is Analytics? The term analytics is not used consistently and it is used at least three different related ways [17]. The initial point for understanding analytics is to explore its roots. In 1970 Decision support systems (DSS) are used to support decision making [14] this DSS used as a description for an application and an academic discipline. The additional decision support applications such as executive information systems, online analytical process (OLAP). And dashboards become popular. Then in 1990 Howard Dresner, an analyst at Gartner, introduced the term Business Intelligence (BI). The BI is broad category of applications, technologies and processes for gathering, storing, accessing and analyzing data to help business users make better decisions [18]. With the definition, BI can be viewed as an umbrella term for all applications that support decision making and interpreted in industry, and increasingly in academic. BI evolved from DSS and thus analytics is an umbrella term for data analysis applications. BI can also referred as "getting data in" (to a data mart or warehouse) and "getting data out" (analyzing the data that is stored), and "rocket science" algorithm (e.g. machine learning, neural networks) to analyze data. The differences take on analytics but normally cause much confusion on the context which makes the meaning clear. The progression from DSS to BI to analytics as shown in Fig.1.

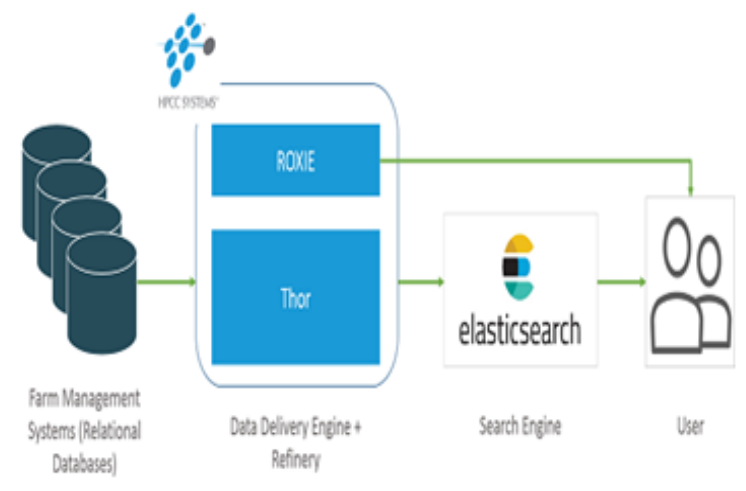

Fig.1 Architecture Overview
4. Different Kinds of Analytics: There are three kinds of analytics due to different applications, technologies and architectures are used for big data analytics. Some analytics are better performed on some platforms than others.

i) Descriptive Analytics: Like reporting/ OLAP, dashboards/scorecards, and data visualization, have been widely used for some time, and are the core applications of traditional BI. Descriptive analytics area unit backward wanting (like a car's rear read mirror) and reveal what has occurred. One trend, however, is to incorporate the findings from predictive analytics, like forecasts of future sales, on dashboards/scorecards.

ii) Predictive Analytics: Counsel what is going to occur within the future (like searching through a car's windshield).The strategies and algorithms for predictive analytics like regression analysis, machine learning, and neural networks have existed for some time. Recently, the software products like SAS Enterprise miner has created them to understand easily. They have additionally integrated into specific applications, like campaign management. Marketing is that the target for several predictive analytics applications; here the goal is to understand clients and their wants and preferences. Some ask the exploratory or discovery analytics, though these are simply alternative names for predictive analytics. When these terms are used, they refer to finding relationships in big data that weren't previously known. The ability to analyze the data source that is, big data creates further opportunities for insight and is particularly necessary for companies with huge amounts of client data.

iii) Golden Path Analysis: could be a new and attentiongrabbing predictive or discovery analytics technique. It involves the analysis of large quantities of active data (i.e., data related to the activities or actions of people) to spot patterns of events or activities that foretell Customer actions like not restore a cellular phone contract, closing a bank account, or abandoning associate in nursing electronic pushcart. When an organization will predict behaviour, it may suggest, and change the anticipated behaviour. Whereas predictive analytics tells you what is going to happen, prescriptive analytics suggests what to to (like a car's GPS instructions). Prescriptive analytics will determine optimum solutions, usually for the allocation of scarce resources. It is researched in domain for a protracted time however is currently finding wider use in observe. For example, the use of mathematical programming for revenue management is progressively common for organizations that have "perishable" goods merchandise like rental cars, hotel rooms and airline seats For example, Harrah's entertainment, a leader within the use of analytics, has been exploitation revenue management for hotel valuation for several years. Organizations usually move from descriptive to predictive to prescriptive analytics. Another way to describe this progression is what happened? Why did it happen? What will happen? How can we make it happen? This progression is often seen in numerous metal and analytics maturity models [6]. 


\section{STUDY AREA}

A. Climatic Limitations: Climate contains a major, and in places preponderant, influence onto land quality by affect in the range of potential agricultural uses and also the price and level of production. Its most elementary influence is on the potential for plant growth, by decisive the energy offered for photosynthesis and water to plant roots. The effect on plant growth occurs partly through interactions with soil and site properties which determine soil wetness and doughtiness [5]. There are also more direct effects on crops or stock such as exposure to damaging wind, persistent wetness or high humidity and frost which can cause physical damage, disease or stress. It is therefore necessary to include in the ALC an assessment of the overall climatic limitation in addition to the interactive limitations which are assessed separately.

The climatically criteria are thought about initial once classifying land. Climate is preponderant within the sense that severe limitations can prohibit land to low grades no matter favourable soil or site conditions. The general principle followed is to assign increasing degrees of limitation to agricultural use as rainfall will increase and average temperature decreases. Thus, in climatic terms, the poorest areas are both the wettest and coldest and conversely the climate is regarded as more favourable as temperature increases and rainfall moderates.

The main parameters employed in the assessment of the climatically limitation are average annual rainfall (AAR), as a measure of overall wetness; and accumulated temperature, as a measure of the relative warmth of a locality. Accumulated temperature is that the more than daily air temperatures on top of a specific threshold temperature, summed over a specified period. When calculated over Associate in nursing applicable a part of the growing season it is used as a sign of warmth energy input and soil drying potential and has made known correlate with crop growth and yield. Work on grass [13] and cereals [10] showed that leaf extension occurs, albeit slowly, down to temperatures as low as $0^{\circ}$ Celsius, which is adopt of the threshold temperature for the ALC system.

For the climatically assessment, accumulated temperature is calculated, using an established algorithm (Meteorological Office, 1969), for the period January to June (AT0); this being the critical growth period for most crops. The top of parameters gives the idea for the analysis of overall climate. Local climatic factors including aspect, exposure and frost risk are also considered when grading land but are not easily quantified and require careful judgment for individual sites.

B. Assessment of the Overall Climate Limitation: The allowed combinations of AAR and AT0 for each ALC grade and sub grade are defined graphically in Fig.2. The AAR and AT0 datasets used in the assessment of the climate, doughtiness and wetness limitations. To provide consistency in those assessments a standard data source is required for the calibration and operation of the system. Traditionally, maps or meteoric station information are accustomed estimate climatic condition at a site. However, the manual interpretation of maps or extrapolation of values from recording stations to sites under investigation involves subjective judgments, and even where data are available from a nearby meteorological station it cannot be assumed that the station worth is representative of the encircling space.

A number of grid point datasets with a spacing of $5 \mathrm{~km}$ have therefore been developed covering the whole of England and Wales and standard methods have been devised for estimating the worth of every parameter at any location. The grid is coincident with the $5 \mathrm{~km}$ intervals of the Ordnance Survey National Grid, having its origin south-west of the Scilly Isles. The use of grid point data has significant advantages for computerized storage and manipulation of information. The datasets are held in Land, it is a computerbased land information system developed by the SSLRC and funded by MAFF. The system can be used to obtain both grid point and interpolated values for specified grid references. The complete dataset will also be published by the Meteorological Office (in press) and the procedure for obtaining interpolated values will be explained in that publication.

C. Climate Datasets: The five agro-climatic parameters used in the ALC system [1] and the associated limitation factors are listed in Table I. The FCD dataset was compiled by the SSLRC on the basis of Meteorological Office data. The other datasets were compiled by the Meteorological Office and processed by the SSLRC prior to their incorporation in LandIS. Datasets of altitude and of average annual rainfall change with altitude (i.e. lapse rate of AAR) are also held on LandIS for use in the interpolation from grid point values to site values. The data sources were as follows:

1. Average Annual Rainfall (AAR): Gridpoint AAR values $(\mathrm{mm})$ were interpolated from unpublished rainfall maps at a scale of 1:250,000 on which the published 1:6, 25,000 maps for 1941-70 was originally based

2. Average Summer Rainfall (ASR): Gridpoint ASR values $(\mathrm{mm})$ were manually interpolated from an unpublished 1:6, 25,000 scale map of average summer rainfall for 1941-70.

3. Median Accumulated Temperature above $0^{\circ} \mathrm{C}$, January to June (ATO): The AT0 dataset is based on temperature data from the 94 stations in the Complete Agromet Database which has complete records over the period 1961- 1980. Accumulated temperatures for the period January to June each year were computed for each station from daily measurements of maximum and minimum temperature and the median value of AT0 in the period 1961-80 was determined. The median values were then extrapolated to gridpoints by means of a regression equation which relates accumulated temperature, altitude, latitude (National Grid northing) and longitude (National Grid easting). The following equation was used: 
TABLE I LIMITATION FACTORS AND ASSOCIATED AGRO CLIMATIC PARAMETERS

\begin{tabular}{|l|l|c|}
\hline Limitation Factor & \multicolumn{1}{|c|}{ Parameter } & Observation period \\
\hline Climate & Average Annual Rainfall (AAR) & $1941-1970$ \\
& Median Accumulated Temperature above 0 ${ }^{\circ}$ C, January to June (AT0) & $1961-1980$ \\
\hline Soil Wetness & Median Duration of Field Capacity Days (FCD) & $1941-1970$ \\
\hline \multirow{2}{*}{ Soil Doughtiness } & Average Summer Rainfall, April to September (ASR) & $1941-1970$ \\
& Median Accumulated Temperature above 0 ${ }^{\circ}$ C, April to September (ATS) & $1961-1980$ \\
\hline
\end{tabular}

AT0 $($ day degrees Celsius $)=1708-1.14 \mathrm{~A}-0.023 \mathrm{E}-0.044 \mathrm{~N}$ Where

A is altitude above mean sea level (meters)

$\mathrm{E}$ is National Grid easting to $100 \mathrm{~m}$ (for significant figures)

$\mathrm{N}$ is National Grid northing to $100 \mathrm{~m}$ (for significant figures)

This equation explains approximately $90 \%$ of the variation in AT0 for the 94 agro meteorological recording stations.

4. Local Climatic Factors: At the local scale variations within the facet, gradient and elevation of the land will considerably modify the general climate, particularly in relation to temperature, exposure and frost risk. Aspect will have a marked influence on the quantity of radiation that a site receives. In general, mean daily temperatures and therefore accumulated temperatures in spring and early summer square measure higher on slopes with secure southerly aspects than on those facing in northerly directions. Radiation intensity additionally varies with slope angle specified variations thanks to facet square measure a lot of marked on steeper slopes. In valleys, the relationships are measured usually a lot of complicated to the impact of shading, which might moderate the advantages of a southerly facet and increase the penalties on north facing slopes.

The influence of a favorable aspect on mean temperatures may be reduced or removed by exposure. In bound things exposure could represent a major environmental condition consider its claim. Persistent robust or cold winds are often damaging to crops or cause stress to stock, especially in wet weather. Upland areas, and land that stands higher the encompassing rural area, are often exposed. Many coastal districts measures are exposed to robust, salt-laden winds and their effects can extend for several miles inland. Wind speed is strongly influenced by topography. In general, wind velocities increase with altitude and decrease with distance from the west coast, while the funneling of winds along valleys, particularly in the uplands, may result in consistently higher wind speeds. The incidence of damaging frost is also closely related to topography and can be localized. Spring frosts can cause serious damage to fruit crops and may check the growth of arable crops. A slope of $2^{\circ}$ is enough to initiate the movement of cold air down slope, and valley bottoms and basin sites are particularly susceptible to frost. The assessment of frost risk is most vital in relevance the higher quality land wherever a lot of sensitive farming crops are measure probably to be grown. Soil [16] type additionally influences frost risk, with sandy and dry peat soils being more prone to late spring frosts than other soils. The interactions between topography and climate measures are usually complicated and it's impractical to allow careful assistance for his or her assessment. Where the overall climate is liable to be modified significantly by local factors, the effect on grading should be assessed on the basis of expert agro meteorological advice.

\section{METHODOLOGY}

For classifying the land AAR and ATO values are derived from the above Fig. 2 and are classified according to AAR and ATO combinations in the given data are as follows: Firstly, we load image in to Mongodb by client server command prompt. Then we analyis the image and found the AAR and ATO values then by the values we find the GRADES of different agriculture land classification as follows:

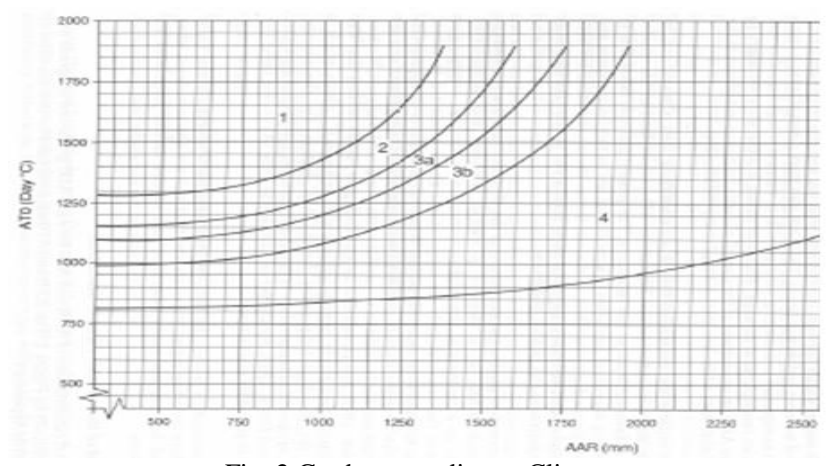

Fig. 2 Grades according to Climate

GRADE 1- represents land soil is good for all cultivations as shown in Fig. 3. Grade 2 -Top soils and sub soils are typically medium, slight doughtiness limits this land as shown in Fig. 4. Grade 3a - Imperfectly drained soils with wetness and workability imitation. GRADE 3b-Poorly drained and has a severe soil wetness and workability limitation. Grade 4-Poorly drained land with a more severe soil wetness limitation than elsewhere on the site as shown in Fig. 5, 6, 7

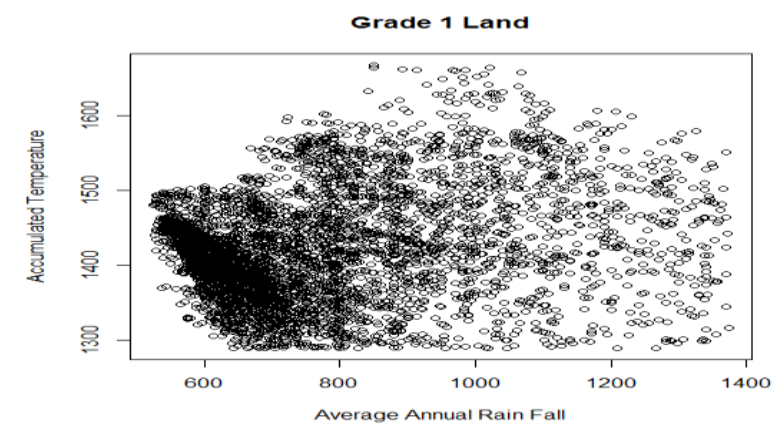

Fig. 3 Grade1 


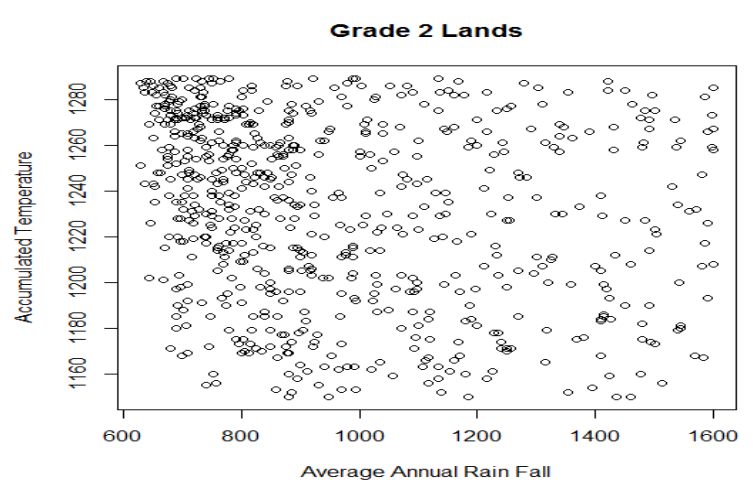

Fig. 4 Grade 2

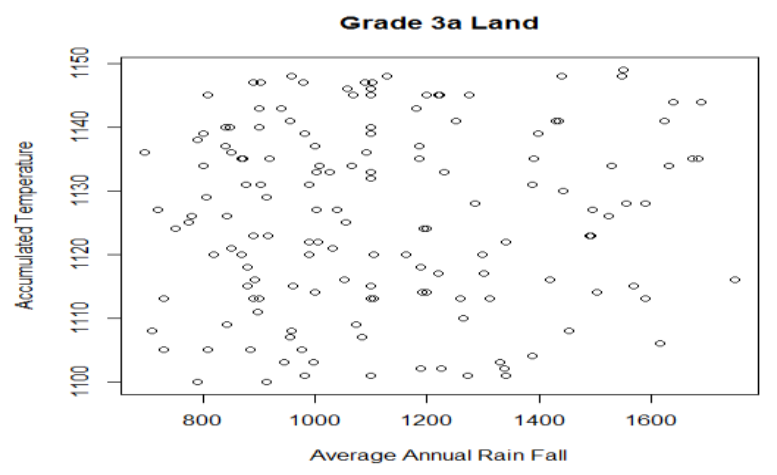

Fig. 5 Grade $3 \mathrm{a}$

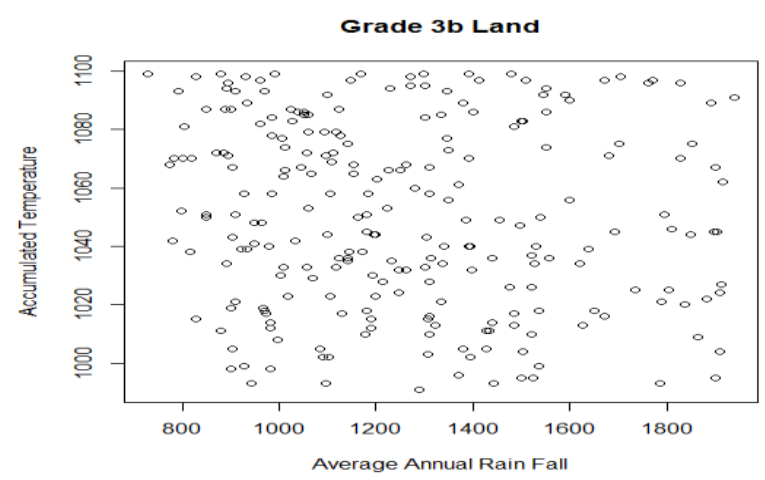

Fig. 6 Grade $3 b$

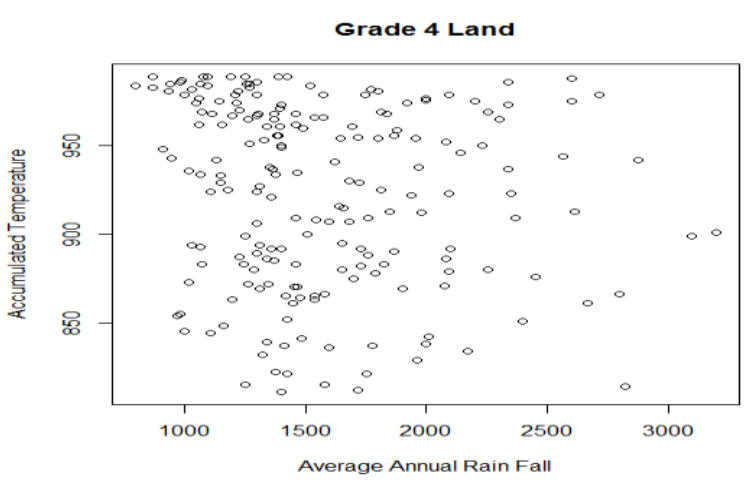

Fig. 7 Grade 4

\section{CONCLUSION}

The rainfall of England and Wales is calculated by climate and temperature using Agriculture land classification. This climatic graph is loaded into Mongo DB and analyzed the values of AAR and ATO using R programming. By using AAR and ATO we find the grades of the agriculture land. Which is in different forms as Grade- 1 as excellent, Grade-2 as very good, Grade-3a as good, Grade-3b as moderate, Grade- 4 as poor. Where these Grades are represented in graphically. The different types of data is taken in the form of documents or in image and calculated using Big data analysis with Mongo DB, Hive, PIG etc. and this loaded data can be accessed in to Python or $\mathrm{R}$ programming. We can also calculate in MAT LAB also. We can also classify the agriculture land with its crops that means at which climate different grades of agriculture land will produce which crop and which area is rich in producing the specified crops and which area is poor in producing the specified crops.

\section{REFERENCES}

[1] B.W and C. L. Bascomb, "Soil Survey Laboratory Methods", Soil Survey Technical Monograph., No.6,1982,

[2] J.S. Bibbyand H.A Douglas, and A.J Thomasson and Robertson, "Land Capability Classification for Agriculture", Macaulay Institute for Soil Research, Aberdeen, 1982.

[3] PeyakuntaBhargavi and SingarajuJyothi, "Big Data and Internet of Things for Analysing and Designing Systems Based on Hyper spectral Images", In Exploring the Convergence of Big Data and the Internet of Things, edited by Prasad, A.V. Krishna, IGI Global, DOI: 10.4018/978-1-5225-2947-7.ch017, 2018.

[4] J.S. Bibby and D. Mackney, "Land Use Capability Classification", Soil Survey Technical Monograph, No.1, 1969.

[5] P J Craull, "A description of urban soils and their desired characteristics", Jaboriculture, Vol. 11, No. 11, 330-39, 1985.

[6] W Eckerson. "Gauge Your Data Warehousing Maturity", DM Review, Vol. 11, No. 14, pp. 34, 2004.

[7] "Agricultural Land Classification of England and Wales", Oct 1988.

[8] Fisher Danyel and Deline Roband Czerwinski Mary and Drucker Steven, "Interactions with Big Data Analytics", Interactions, Vol. 19, No. 3, pp. 50-59, 2012.

[9] B. Franks, "Taming the Big Data Tidal Wave", New York: Wiley, 2012.

[10] P. V. Biscoe," Radiation absorption, growth and yield of cereals", The Journal of Agricultural Science, Vol. 91, No.1, pp. 47-60,1978.

[11] S. Jyothi and K. Sarita and K.R. Manjula, "Classification of Deforestation factors using Data Mining Techniques", International Journal of Computer Science Engineering and Information Technology Research (IJCSEITR), Vol.3, No. 4.

[12] "Agricultural Land Classification Scarborough District Wide Local Plan North Yorkshire", December 1994.

[13] H L Penman, "Natural evaporation from open water, bare soil and grass", Proc. Roy. Soc. Series A, Vol. 193, pp. 120-45, 1948.

[14] D.J. Power, "A Brief History of Decision Support Systems", DSSResources.com, 2007.

[15] "Decision Support Systems Resource"[Online] Available http://DSSResources.com/history/dsshistory.html, version4.0(current Mar7,2014)

[16] P. Russom, "Big Data Analytics", TDWI Best Practices Report. Seattle: The Data Warehousing Institute, Fourth Quarter, [Online] Available at http://tdwi.org/research/2011/09/best-practices-reportq4-big-data-analytics.aspx (current March 7, 2014), 2011.

[17] A J Thomason "Assessment of soil draughtiness. In: Soil Survey Applications" (ed. M G Jarvis and D Mackey), Soil Survey Technical Monograph, No. 13, pp. 43-50, 1979.

[18] H.J. Watson, "All about Analytics", International Journal of Business Intelligence Research, Vol. 2, No. 4, pp.13-28, 2013.

[19] H.J. Watson, "Tutorial: Business Intelligence-Past, Present, and Future", Communications of the Association for Information Systems, Vol. 39, No. 25, 2009. [Online] Available at: http://aisel.aisnet.org/ cais/vol25/iss1/39 (current March 7, 2014). 